\title{
Fuzzy Logic Control Application to Enhance Voltage Stability of the Electric Power Systems
}

\author{
James A. Momoh, Fellow, IEEE, Wenjie Zheng, and Keisha D'Arnaud \\ Center for Systems and Control (CESaC),
}

\begin{abstract}
This paper develops an integrated strategy for maintaining voltage stability for online applications. The proposed strategy employs real time data in the computation of a voltage stability index for voltage stability monitoring and control. The index chosen allows for the fast evaluation of the voltage stability margin for real-time assessment. A fast control operation based on fuzzy logic control is used to determine the VAr compensation required for the mitigation of occurrences of voltage instability.
\end{abstract}

Index Terms - voltage stability, Voltage stability index, fuzzy logic control

\section{INTRODUCTION}

$\mathrm{V}$ oltage stability is of major concern in modern power systems, which are steadily approaching the operating limits imposed by economic and environmental constraints. The expansion of the conventional power system allows for incidences where unexpected contingencies to go unconsidered, particularly due to the interties in power systems. It is, therefore, difficult to predefine all the outages and complexities and control counterparts. Stability, security and efficiency are of utmost importance in planning and operating the power systems [1]. In response to a disturbance, power consumed by the loads tends to be restored, and this correspondingly increases the stress on the high voltage network by increasing the power consumption beyond the capacity of the transmission network for power transfer and voltage support and usually lead to the most common form of voltage instability, the progressive drop of bus voltages [2]. The voltage drop of some buses may lead to voltage collapse or blackout in the end. The ability to rapidly monitor and be adaptive to system changes for restoring an equilibrium point in between generation and load balance is the goal of voltage stability assessment and control [3, 4].

Fast online assessment and control implementations, involving Phasor Measurement Units (PMUs) have been utilized in recent works [14-21]. Real-time measurements via PMUs provide a fast and accurate way to track the load dynamics in addition to the current monitoring devices. The on-line application not only requires a fast detection ability but

J. A. Momoh is the Director of the Center for Energy Systems and Control $(\mathrm{CESaC})$ and a Professor at the Department of Electrical and Computer Engineering (ECE), Howard University, Washington, DC, 20059 USA (phone: 202-806-5350; fax: 202-806-6588; e-mail: jmomoh@howard.edu).

Wenjie Zheng is a doctoral visiting student at $\mathrm{CESaC}$, Howard University, Washington, DC, 20059, (e-mail: scutcheng@gmail.com).

Keisha D'Arnaud is a Masters student at CESaC, Howard University, Washington, DC, 20059. a fast calculation scheme.

Both dynamic and static analysis techniques are introduced to study the voltage instability scenarios and many algorithms have been developed for control. Several implementations have been done in areas of corrective control for static voltage stability [4-12] and traditionally focus on off-line studies in power system planning design and operation. Better management and control of the power system is required and thus necessary to develop some practical real-time strategies to make a compromise between accuracy and computation efficiency. Due to the fact that uncertainties come from system model and date inaccuracy are both represented by probability. Fuzzy control method can be used to capture the instability scenarios as additional to the accurate model analysis, this is applicable especially for contingency that fast determination is required instead of precise control outputs. Seldom literature shows fuzzy logic control used as an integrated scheme with the voltage instability assessment [13].

This paper therefore develops an integrated strategy for implementation of fast on-line voltage instability detection and control to capture the voltage instability. The proposed method builds on recent advance in the areas of real-time voltage stability monitoring and control assume that the measurement data can be obtained fast and accurate enough. The strategy will permit the computation of real-time controls such as adjustments of set-points of the automatic voltage regulators (AVRs) or shunt capacitor banks and even load shedding which are commonly used to arrest voltage instability at its onset. The remainder of the paper is organized as follows. In Section II discuss the selected index for voltage stability computation and the corresponding Fuzzy Control method. Proposed algorithm is given in section III and the simulation result based on PHCN 30-bus test system is presented in Section IV. Subsequent sections summarized discussions and conclusions.

\section{Voltage Stability Measurement TeChniQues AND FUZZY LOGIC CONTROL}

\section{A. PMU Technology}

Phasor Measurement Units (PMUs) are widely employed by power system engineers and operators for Wide-Area Measurement (WAMS) and control (WACS) applications [2223]. Through the use of integral GPS receiver clocks, PMUs sample synchronously at selected locations throughout the power system with high precision time tag. Input signals from $\mathrm{CT}$ and PT secondaries are isolated, filtered and sampled at an 
effective rate of tens times of the fundamental frequency. A recursive Discrete Fourier Transformation(DFT) is used to calculate the local positive sequence component from the sample data.

In recent years, significant attention has been given to the methods that use direct parametric (load) dependence to estimate the proximity of a power system to the voltage collapse. Some authors propose phasor-measurement-based algorithms to determine voltage collapse proximity.

With great accurate synchronized measurements of phase angles throughout the system, we can fast evaluate the current voltage status by an effective way named voltage stability index.

\section{B. Voltage Stability Index (VSI)}

Many indices for categorizing voltage stability in static security stability assessment in power systems have been developed over the years. Most of them are defined by the current operating point to different stability boundaries or collapse point and are typically based on sensitivity techniques and multiple load flow results. Techniques such as the Voltage Collapse Proximity Indicator (VCPI), Voltage Instability Predictor Index (VIPI) by Tamura, energy method, $L$-Indicator derived from load flow and continuation power flow, and an Integrated Logarithmic Index (ILI) are some typical methods for assessing static voltage instability problems. Here we employ the L-index which amongst the options is advantageous as it allows for the fast and easy calculation and quantification of voltage stability for every operating point.

The transmission system can be represented using a hybrid representation, by the following set of equations

$$
\left[\begin{array}{c}
V_{L} \\
I_{G}
\end{array}\right]=H\left[\begin{array}{l}
I_{L} \\
V_{G}
\end{array}\right]=\left[\begin{array}{ll}
Z_{L L} & F_{L G} \\
K_{G L} & Y_{G G}
\end{array}\right]\left[\begin{array}{c}
I_{L} \\
V_{G}
\end{array}\right]
$$

where $V_{L}, I_{L}$ are the voltage and current vectors at the load buses. $V_{G}, I_{G}$ are the voltage and current vectors at the generator buses. $Z_{L L}, F_{L G}, K_{G L}, Y_{G G}$ are the sub-matrices of the hybrid matrix $H$. The $H$ matrix can be evaluated from the $\mathrm{Y}$ bus matrix by a partial inversion, where the voltages at the load buses are exchanged against their currents.

The index $\mathrm{L}_{\mathrm{j}}$ can be derived and expressed in terms of the power terms as the following.

$$
L_{j}=\left|\frac{\stackrel{*}{S}_{j+}}{Y_{j j+} V_{j}^{2}}\right|
$$

where,

$$
S_{j+}=S_{j}+S_{j c o r r}
$$

* indicates the complex conjugate of the vector

$$
\begin{aligned}
& S_{j c o r r}=\left(\sum_{\substack{i \in L o a d s \\
i \neq j}} \frac{Z_{j i}}{Z_{j j}} \frac{S_{i}}{V_{i}}\right) V_{j} \\
& Y_{j j+}=\left(Z_{j j}\right)^{-1}
\end{aligned}
$$

The complex power term component $S_{\text {jorr }}$ represents the contributions of the other loads in the system to the index evaluated at the node $\mathrm{j}$.

It can be seen that when a load bus approaches a steady state voltage collapse situation, the index L approaches the numerical value 1.0. Hence for an overall system voltage stability condition, the index evaluated at any of the buses must be less than unity. Thus the index value $\mathrm{L}$ gives an indication of how far the system is from voltage collapse. This feature of the indicator has been exploited in our approach that treated the voltage stability as a constraint in optimal power flow [26].

Fast evaluation of the voltage stability index enable more time for the control determination, so that a efficient control determination strategy is required. Fuzzy logic control serve as an alternative to the traditional way and give out the calculation result by compromising between efficiency and accuracy.

\section{Fuzzy Set Theory and Fuzzy Logic Control(FLC)}

Based on the L-index and its change ratio we implement a fuzzy inference rule to quickly determine the corresponding mitigation control. Though not very accurate, fuzzy control functions to maintain stability, which is of greatest importance during contingency. The basic concepts and methodology of the fuzzy control implementation is itemized below.

\section{1) Classical Sets and Fuzzy Sets}

Let $X$ be the universe of discourse with elements $x, A$ is the sub-set of $X$, named fuzzy set. Membership of $\mathrm{x}$ in classical set $\mathrm{A}$ can be viewed as a characteristic function $\mu_{A}$ from $\mathrm{X}$ to $(0,1)$ such that

$$
\mu_{A}(x)= \begin{cases}1 ; & x \in A \\ 0 ; & x \notin A\end{cases}
$$

For a fuzzy set A of the universe X, the degree of membership of $\mathrm{x}$ is defined as:

$$
\mu_{A}(x) \in[0,1]
$$

Where $\mu_{A}(x)$ is a curve that defines how each point in the input space is mapped to a membership value between 0 and 1 . The more $\mathrm{x}$ belongs to $\mathrm{A}$, the closer the value of $\mu_{A}(x)$ is to 1.

Fuzzy set elements are ordered pairs indicating the value of a set element and the degree of membership:

$$
A=\left\{\left(x, \mu_{A}(x) \mid x \in X\right\}\right.
$$

L-index can be directly linked to the table lookup or a function evaluation. The change ratio of the L-index can be used as another input. Different kinds of membership function curves should be chosen according to our knowledge and make some necessary modification. It is necessary to take the input and determine the degree to which they belong to the fuzzy set according to the membership functions(MFs) and they should be limited to the universe of discourse 


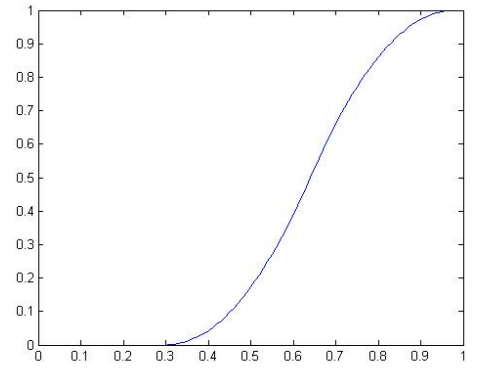

Fig.1. The Membership Function for L-index

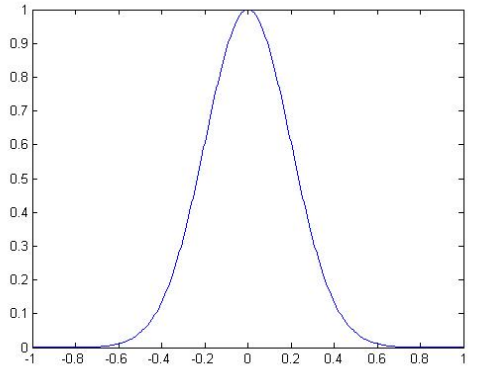

Fig.2. The Membership Function for L-index change ratio

Here, we employ the s-shape to handle L-index as an input, as showed in Fig.1, on the other hand, assume that we sample the L-index every second, using the real-time monitoring technology, one can have a higher sampling rate. The L-index, which ranges between $[0,1]$ should be mapped into $[-1,1]$ using the simple function $2 \mathrm{x}-1=\mathrm{y}$ and the change rate of the $\mathrm{L}$ index is subject to $[-1,1]$ and the membership function is showed in Fig.2.

\section{2) Fuzzy set operations}

For two fuzzy sets A and B, their union operation is defined as:

$$
\mu_{A \cup B}(x)=\max \left\{\mu_{A}(x), \mu_{B}(x)\right\}
$$

The intersection operation is:

$$
\mu_{A \cap B}(x)=\min \left\{\mu_{A}(x), \mu_{B}(x)\right\}
$$

The component operation is:

$$
\mu_{\bar{A}}(x)=1-\mu_{A}(x)
$$

Other operations can be defined, T-norm and s-norm is most often used in particular operations [24]. In addition, to perform certain mathematical operations, a crisp set may be required. The following definition of an $\alpha$-cut can be used to create a family of crisp sets from a given fuzzy set:

$$
\mu_{A_{\alpha}}(x)= \begin{cases}1 ; & \text { if } \mu_{A}(x)>\alpha \\ 0 ; & \text { otherwise }\end{cases}
$$

Furthermore, a particular useful mathematical construct is the fuzzy relation. A fuzzy binary relation is defined as:

$$
R=\left\{\left(x, y, \mu_{R}(x, y)\right) \mid x \in X, y \in Y\right\}
$$

For a fuzzy relation $\mathrm{R}$, there is the following fuzzy composition computation:

$$
\mu_{y}(y)=\sup _{y \in Y}\left\{\min \left[\mu_{R}(x), \mu_{R}(x, y)\right]\right\}
$$

\section{3) Fuzzy Measures}

Fuzzy measures are criteria for measuring attributes of objects. When a certain set $\mathrm{X}$ is considered, the function $\mathrm{g}$ that makes subsets $\mathrm{E}$ and $\mathrm{F}$ correspond to the value in the interval $[0,1]$ are called fuzzy measures if they have the following properties:

$$
\begin{aligned}
& g(\phi)=0, g(x)=1 ; \\
& \text { If } E \in F, g(E) \leq g(F) ; \\
& \text { or } g(E \cup F) \geq \max (g(E), g(F)) ; \\
& \text { if } E_{1} \leq E_{2} \leq \ldots \text { or } E_{1} \geq \mathrm{E}_{2} \geq \ldots ; \\
& \lim _{x \rightarrow \infty}\left(g\left(E_{n}\right)\right)=g\left(\lim _{x \rightarrow \infty}\left(E_{n}\right)\right)
\end{aligned}
$$

Fuzzy measures are monotonic set functions, $g$ is referred to as a possibility measure. In solving practical problems, it is an important to adopt the appropriate fuzzy operators or new operators can be constructed to reflect the expert's reasoning [25]. The Rule's weight must be determined before the application of the implication method. Here, for simplicity, we choose 1 for each rule. Usually, we employ the following rules as shown in Table 1.

\section{TABLE.1 FUZZY LOGIC RULES}

(Remarks: LN: Large Negative, MN: Medium Negative, SN: Small Negative, ZE: Zeros, SP: Small Positive, MP: Medium Positive, LP: Large Positive)

\begin{tabular}{|l|l|l|l|l|l|l|l|}
\hline WC & LN & MN & SN & ZE & SP & MP & LP \\
\hline LN & LP & LP & LP & MP & MP & SP & ZE \\
\hline SN & LP & MP & MP & MP & SP & ZE & SN \\
\hline SN & LP & MP & SP & SP & ZE & SN & MN \\
\hline ZE & MP & MP & SP & ZE & SN & MN & MN \\
\hline SP & MP & SP & ZE & SN & SN & MN & LN \\
\hline MP & SP & ZE & SN & MN & MN & MN & LN \\
\hline LP & ZE & SN & MN & MN & LN & LN & LN \\
\hline
\end{tabular}

4) Fuzzy logic control

Fuzzy set theory provides benefits over the traditional methods and provides a compromise between conflicts, which are usually treated as weights coefficients but sometimes not easy to find the solutions. Due to the fact that fuzzy logic based controllers are not wholly dependent on the model, they are more robust and adaptive, and should be promising in dealing with unexpected contingencies.

Here L-index and its change ratio are fuzzified via membership function to calculate the corresponding control according to fuzzy logic inference rules in Table.1.

\section{PROPOSED AlgORITHM}

\section{A. Voltage stability monitoring}

This paper develops an integrated strategy of real time measurement and voltage stability improvement control for online applications in power engineering. The overall application of the proposed control strategy is shown in Fig. 3.

For a specific time, $T_{i}$, the strategy of real time voltage stability improvement is done in the following steps: 
1) Determine the system base case data and establish feasibility of load flow based on the real time measurement data from PMU.

2) Determine system data that reflect load changes over time (and/or contingencies) affecting the voltage profile.

3) Compute the voltage stability index, L-indicator, based on the parameter measurement of the power system under observation, and at time $T_{i+1}$, also calculate the change ratio of L-index.

4) Determine the violation of voltage stability limits. If the violation is detected, the isolated node or the cluster of observable nodes that contribute most to the degradation of the voltage stability margin with close proximity to its limit or threshold will be located.

5) The control result from fuzzy inference system will be used as mitigation strategy for the voltage drop down. If necessary, more remedial controls will be applied in case of emergencies.

6) Move to the next time window and repeat the steps from step 1 .

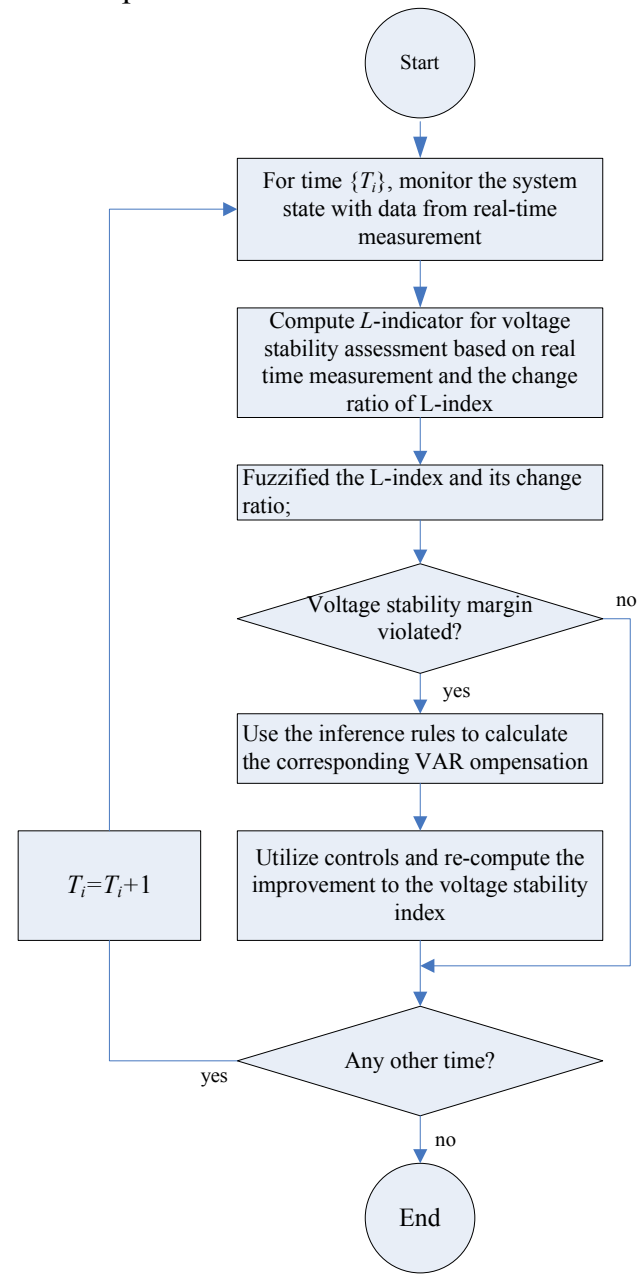

Fig.3. Procedure for voltage stability monitoring, assessment and control

The design strategy will permit the computation of realtime controls such as adjustments of automatic voltage regulators set-point or controllable series/shunt compensators commonly used to capture voltage instability at its onset.

\section{Test System Topology AND Simulation REsults}

\section{A. Test System}

The test system used in this research work was the PHCN 30-bus HV transmission system model that with 50 branches and 7 generators.

This system has several controls for handling voltage problem and they include generation dispatch and tap changing transformers. The base case for active and reactive load is $2859 \mathrm{MW}$ and 1773 MVAR, respectively, and the system power and voltage bases are 100 MVA and 330-kV.

\section{B. Weak Voltage Nodes for Monitoring}

A load duration curve representing base cases suffering an exponential increase from $100 \%$ loading levels were used. Power flow results at the base case and lower did not result in any voltage security or thermal overload in the branches and transformers.

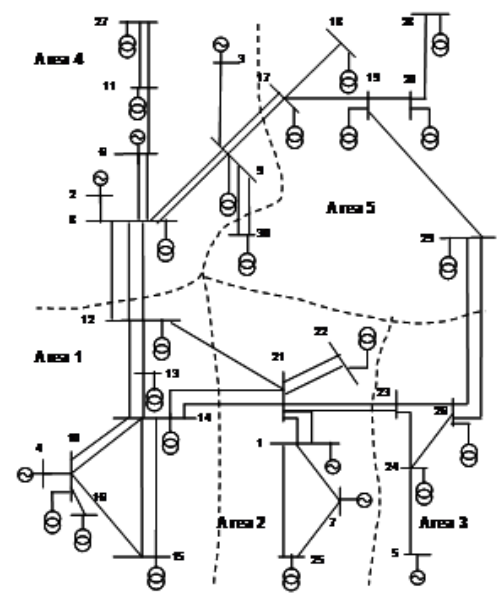

Fig.4. PHCN 30-bus 330KV HV System

Simulation results showed that the most vulnerable buses in the systems are 28, 20,19, and 29. This result is based on power flow results of simulating the system over different time-scales of load changes.

In this paper, bus 28 and bus 20 are monitored to represent the most severe cases under consideration. This is necessary if recommending appropriate placement of monitoring devices with effective observability of the network.

\section{System performance under different loading conditions}

Fig. 5 shows the voltage trajectory of bus 28 and bus 20 from time $0 \mathrm{sec}$ to $20 \mathrm{sec}$ under the asymptotic growth of the load at all the load buses from $5^{\text {th }} \mathrm{sec}$. The load is supposed to be growing in an slowly exponential pattern. Bus 20 and 28 are recognized as the weak points for voltage stability after many pre-posting load flow calculation.

With the load increase, the voltage profile is becoming worse with the $L$-index increasing.

Table. 2 shows the L-index at three sample time to demonstrate the VSI. We can easily notice that without any remedial control, the voltage profile suffer a asymptotic drop and the voltage collapse at about 20 seconds. 


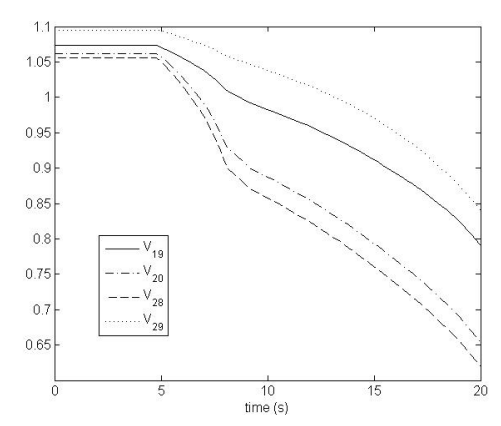

Fig.5. Voltage profile without control

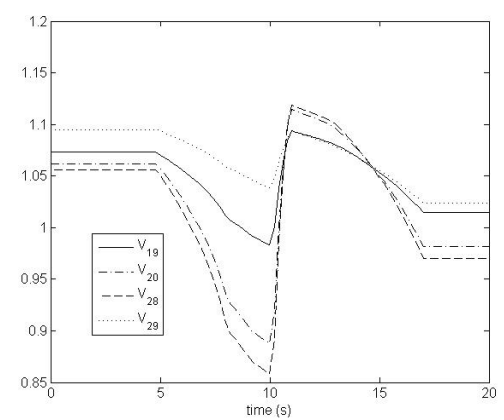

Fig.6. Voltage profile with VAR compensation

TABLE.2 SUMMARY OF MONITORED WEAK NODES AND THE SYSTEM Voltage STABILITY INDICES

\begin{tabular}{|c|c|c|c|c|c|}
\hline $\begin{array}{c}\text { Case } \\
\text { (time) }\end{array}$ & \multicolumn{3}{|c|}{ Bus voltage magnitude, $\left(\left|V_{i}\right|\right.}$, & \multirow{2}{*}{$\begin{array}{c}\text { L-index } \\
\text { values }\end{array}$} \\
\hline $0 \mathrm{~s}$ & 1.07291 & 1.06192 & 1.05557 & 1.09513 & 0.496 \\
\hline $5 \mathrm{~s}$ & 1.07037 & 1.05692 & 1.04978 & 1.09352 & 0.496 \\
\hline $10 \mathrm{~s}$ & 0.98308 & 0.88743 & 0.85779 & 1.03827 & 0.7634 \\
\hline $15 \mathrm{~s}$ & 0.9116 & 0.79339 & 0.76089 & 0.97047 & 0.9131 \\
\hline
\end{tabular}

TABLE. 3 Voltage ENHANCEMENT

\begin{tabular}{|c|c|c|c|c|c|}
\hline $\begin{array}{c}\text { Case } \\
\text { (time) }\end{array}$ & \multicolumn{3}{|c|}{ Bus voltage magnitude, $\left(\left|V_{i}\right|\right.}$, & \multirow{2}{*}{$\begin{array}{c}\text { L-index } \\
\text { values }\end{array}$} \\
\hline $11 \mathrm{~s}$ & 0.98082 & 0.8843 & 0.85454 & 1.03623 & 0.7317 \\
\hline $15 \mathrm{~s}$ & 0.98082 & 0.8843 & 0.85454 & 1.03623 & 0.6696 \\
\hline $20 \mathrm{~s}$ & 0.98082 & 0.8843 & 0.85454 & 1.03623 & 0.6408 \\
\hline
\end{tabular}

Fuzzy inference then makes a fast decision in order the capture the drop of the voltage trajectory and steer it back to the acceptable level and gain the time for operators and engineers to make further decisions.

The L-index is sample every second and the change ratio of the index can be calculated immediately without any effort. Both are used as the input for the Fuzzy Logic Controller. The compensation control functions at $10^{\text {th }}$ second and it can be run continuously, but here for simple purpose, we just calculate the mitigate control for one time. Fig.6 shows the voltage profiles after some shunt capacitor banks are connected the corresponding bus and they provide the reactive support for the system. We suppose that the compensation buses are 18, 19, 20, 28, 26, 29, 13, 14, 15, 16, respectively. The maximum available VAR compensation capacity at each bus is assumed to be 0.3 p.u.
Though the index cannot recover to the pre-fault condition, it shows that with the shunt capacitor banks switched, it effectively delay or prevent the drop of the voltage at the weak point of the network. Furthermore, load shedding should be taken into consideration to coordinate with the VAR compensation while the capacitor banks can not alleviate the voltage drop. The high sampling rate of the real-time measurement devices strongly supports this fast monitoring and calculation integrated strategy.

The resulting improved voltage profiles for these buses as well as the new $L$-indices are included in Table 3.

\section{CONCLUSIONS AND DISCUSSIONS}

The paper develops an integrated method for real time assessment and control for voltage stability. The proposed method builds on recent advancement in the areas of real-time voltage stability monitoring and data acquisition. The proposed strategy will permit the computation of real-time controls such as adjustments of voltage regulators or controllable series/shunt compensators commonly used to arrest voltage instability at its onset.

This research work is an ongoing work that is currently being extended to include intelligent systems for mitigating voltage instability. In the future, adaptive dynamic optimization will be introduced to meet the multiple objectives. Initial results have shown promise in this important direction that is of interests and valuable to the utilities.

\section{ACKNOWLEDGMENTS}

The authors wish to acknowledge the funding received from the National Science Foundation (NSF) under Grant Award ECCS-0601636.

We would also like to thank the support received from students and staff working on the project at the Center for Energy Systems and Control (CESaC), an interdisciplinary research and education Center located at Howard University, Washington, DC.

\section{REFERENCES}

[1] IEEE/CIGRE, Joint Task Force on Stability Terms and Definitions, "Definition and classification of power system stability," IEEE Trans. Power Syst., vol. 19, no. 3, pp. 1387-1401, Aug. 2004.

[2] T. V. Cutsem, C. Vournas. "Voltage stability of electric power systems," Kluwer Academic Publishers, 1998.

[3] G. K. Morison, B. Gao, and P. Kundur, "Voltage stability analysis using static and dynamic approaches," IEEE Trans. Power Syst., vol. 8, no. 3, pp. 1159-1171, Aug. 1993.

[4] H. Glavitsch, "Voltage Stability and Collapse - A Review of Basic Phenomena and Methods of Assessment," in Proc. Bulk Power System Voltage Phenomena III Voltage Stability, Security, and Control, August, 1994, pp. 9-14.

[5] I. Smon, G. Verbic, and F. Gubina, "Local Voltage-Stability Index Using Tellegen's Theorem," IEEE Transactions on Power Systems, vol. 21, no. 3, pp. 1267-1275, August 2006.

[6] G. K. Morison, B. Gao, and P. Kundur, "Voltage stability analysis using static and dynamic approaches," IEEE Trans. Power Syst., vol. 8, no. 3, pp. 1159-1171, Aug. 1993.

[7] M.H. Haque, "Determination of Steady-State Voltage Stability Limit Using P-Q Curve", IEEE Power Engineering Review, Apr. 2002, pp. 71-72.

[8] P. Kessel and H. Glavitsch, "Estimating the Voltage Stability of a Power System", IEEE Trans. on Power Delivery, Vol. 1, No. 3, Jul. 1986, pp. 346-354. 
[9] Z. Jia and B. Jeyasurya, "Contingency Ranking for On-Line Voltage Stability Assessment”, IEEE Trans on Power Systems, Vol. 15, No. 3, August 2000.

[10] Z. Yang and P. Cao and M. L. Crow, "A New Computationally Efficient Index for Loadibility Limit studies", Electric Machines and Power Systems, Vol. 28, pp. 385-397.

[11] C. Belhadj, R. Mohaimedi, S. Lefebvre, P. Lagad, Xuan-Dai Do, "Voltage Stability Modeling and Real-Time Monitoring Using Expert System for Operation Assistance," IEEE Transactions on Power Systems, vol. 11, no. 2, pp. 1037-1045, May 1996.

[12] J. A. Momoh, Y. M. Makarov, and B. Mittelstadt, "A Framework for Voltage Stability Assessment in Power System Reliability," IEEE Transactions on Power Systems, vol. 14, pp. 484-491, 1999.

[13] J. A. Momoh, K. Tomsovic, "Overview and Literature Survey of Fuzzy Set Theory in Power Systems," IEEE Transactions on Power Systems, Vol. 10, pp. 1676-1690, 1995

[14] A. G. Phadke, "Synchronized phasor measurements $\sim$ a historical overview," Proceedings of the Transmission and Distribution Conference and Exhibition 2002:Asia/Pacific, Vol. 1, pp. 476-479

[15] A. G. Phadke, "Synchronized phasor measurements in power systems," IEEE Comput. Appl. Power, vol. 6, no. 3, pp. 10-15, Apr. 1993.

[16] C. W. Taylor, "The Future in On-Line Security Assessment and WideArea Stability Control," IEEE Power Engineering Society Winter Meeting, vol. 1, pp. 78-83, 2000.

[17] L. Zhao, A. Abur, "Multiarea State Estimation Using Synchronized Phasor Measurements," IEEE Transactions On Power Systems, vol. 20, no. 2, May 2005.

[18] B. Miľosevic, and M. Begovic', "Voltage-Stability Protection and Control Using a Wide-Area Network of Phasor Measurements," IEEE Tran. on Power Systems, vol. 18, no.1, pp. 121-127, February 2003.

[19] M. La Scala, M. De Benedictis, S. Bruno, A. Grobovoy, N. Bondareva, N. Borodina, and D. Denisova, A. J. Germond, R. Cherkaoui, "Development of Applications in WAMS and WACS: an international cooperation experience," Power Engineering Society General Meeting, vol., Issue, 18-22, 10 pp., June 2006.

[20] C. Rehtanz, J. Bertsch, "Wide Area Measurement and Protection System for Emergency Voltage Stability Control," IEEE Power Engineering Society Winter Meeting, vol 2, pp. 842- 847, 2002.

[21] C. Belhadj, R. Mohaimedi, S. Lefebvre, P. Lagad, Xuan-Dai Do, "Voltage Stability Modeling and Real-Time Monitoring Using Expert System for Operation Assistance," IEEE Transactions on Power Systems, vol. 11, no. 2, pp. 1037-1045, May 1996.

[22] C.W. Taylor, D.C. Erickson, K.E. Martin, R.E. Wilson and V. Venkatasubramaniam, "WACS - Wide area stability voltage control system: R and D and online demonstration," Proc. of IEEE, vol. 93, no. 5, pp892-906, May 2005.

[23] J.H. Chow, A. Chakrabortty, M. Arcak, B. Bhargava, and A. Salazar, "Synchronized Phasor Data Based Energy Function Analysis of Dominant Power Transfer Paths in Large Power Systems," IEEE Transactions on Power Systems, Vol. 22, pp. 727-734, no. 2, May 2007.

[24] A. Kandel, "Fuzzy Mathematical Techniques with Applications," Addison-Wesley, MA, 1986.

[25] H.J. Zimmermann, "Fuzzy set theory and its applications, 3rd edition," Kluwer Academic Publishers, Boston/Dordrecht/London, 1996.

[26] James Momoh, Yan Xia, Garfield Boswell. "Voltage Stability Enhancement using Phasor Measurement Unit(PMU) Technology," The 40th North American Power Symposium, Calgary, Canada, Sept 28th to 30th, 2008.

\section{BIOGRAPHIES}

James A. Momoh (M'76-SM'89-F'99) received the B.S.E.E. degree from Howard University, Washington, D.C., the M.S.E.E. degree from Carnegie Mellon University, Pittsburgh, PA, the M.Sc. degree in systems engineering from the University of Pennsylvania, Philadelphia, and the Ph.D. in electrical engineering from Howard University, in 1975, 1976, 1980, and 1983, respectively. He is a former Program Director in the Engineering Directorate of the Division of Electrical Communication and Systems (ECS) at the National Science Foundation (NSF) in Arlington, VA.

$\mathrm{He}$ is also former Chairman of the Electrical Engineering Department at Howard University, and is the Director of the Center for Energy Systems and Control (CESaC) at Howard University. His research interests include power system reliability and power system optimization, automation and intelligent systems, and economics and risk assessment in a deregulated power system environment. He is currently developing an interdisciplinary research/ education program in power, economics, regulation, and environmental adaptive systems. Dr. Momoh has received several awards/honors including the 1987 Presidential Young Investigator Award, and was the recipient of the 1989 ASEE Excellence Educator.

Wenjie Zheng received the B.Sc from Nanjing University of Science and Technology, Nanjing, in 2004, he is a Ph.D student in South China University of Technology, Guangzhou. Currently, funded by the Chinese Scholarship Council and the National Natural Science Foundation of China, he is a visiting student in the Center for Energy System and Control (CESaC), Howard University. His areas of interest are power system analysis, operation and control, Long-term voltage stability simulation, assessment and control.

Keisha D'Arnaud received the B.Sc degree from the Electrical and Computer Engineering Department at Howard University. She is currently a graduate student at Howard University, pursuing a master's degree with a focus in Power Systems. Her research interests are in the areas of Renewable Energy, electric systems power quality and network quality and network performance. 